\title{
Mycobiota and Natural Incidence of Aflatoxins, Ochratoxin A, and Citrinin in Indian Spices Confirmed by LC-MS/MS
}

\author{
Punam Jeswal and Dhiraj Kumar \\ Post-Graduate Department of Biotechnology, A. N. College, Patna, Bihar 800013, India \\ Correspondence should be addressed to Dhiraj Kumar; dhirajbiotech@yahoo.in
}

Received 5 May 2015; Revised 12 June 2015; Accepted 16 June 2015

Academic Editor: Maurizio Sanguinetti

Copyright ( 2015 P. Jeswal and D. Kumar. This is an open access article distributed under the Creative Commons Attribution License, which permits unrestricted use, distribution, and reproduction in any medium, provided the original work is properly cited.

\begin{abstract}
Nine different Indian spices (red chilli, black pepper, turmeric, coriander, cumin, fennel, caraway, fenugreek, and dry ginger) commonly cultivated and highly used in India were analysed for natural occurrence of toxigenic mycoflora and aflatoxins (AFs), ochratoxin A (OTA), and citrinin (CTN) contamination. Aspergillus flavus and Aspergillus niger were the most dominant species isolated from all types of spices. Red chilli samples were highly contaminated with aflatoxins (85.4\%) followed by dry ginger (77.7\%). 56\% Aspergillus flavus from red chilli and 45\% Aspergillus ochraceus from black pepper were toxigenic and produced aflatoxins and ochratoxin A, respectively. Qualitative detection and quantitative detection of mycotoxins in spices were analyzed by ELISA and further confirmed by LC-MS/MS. Penicillium citrinum produced citrinin in red chilli, black pepper, coriander, cumin, fenugreek, and dry ginger samples. The highest amount of AFs was found in red chilli (219.6 ng/g), OTA was in black pepper (154.1 ng/g), and CTN was in dry ginger samples $(85.1 \mathrm{ng} / \mathrm{g})$. The results of this study suggest that the spices are susceptible substrate for growth of mycotoxigenic fungi and further mycotoxin production. This is the first report of natural occurrence of citrinin in black pepper and dry ginger from India.
\end{abstract}

\section{Introduction}

Spices are cultivated worldwide but India is the largest producer and exporter country in the world [1]. Red chilli, black pepper, turmeric, coriander, cumin, fennel, caraway, fenugreek, and dry ginger are common spices used in Indian cuisine. They provide aroma, color, and flavor in food and are generally used as appetizer to enhance the appetite. They are the herbs, obtained from different parts of plants and rich in antioxidant. These spices have also some medicinal properties and are used widely in ayurvedic medicine [2] and household treatments.

Mycotoxins are the toxic secondary metabolites of fungi produced on wide range of consumable substrates. The most common fungal spices that produce mycotoxins belong to Aspergillus, Penicillium, and Fusarium genera. Some species of these genera have potential to produce different mycotoxins such as aflatoxins, ochratoxin, and citrinin. Aflatoxins are naturally occurring secondary metabolites from some species of Aspergillus and they are carcinogenic [3]. OTA and
CTN are also produced by some species of Aspergillus and Penicillium. OTA is hepatotoxic and CTN is nephrotoxic and cooccurrence of these two mycotoxins causes hepatorenal carcinogenesis $[4,5]$.

Mycotoxin contamination especially aflatoxins contamination in cereals, pulses, oil-seeds, and agricultural products is well known but fragmentary reports are available regarding mycoflora and mycotoxins contamination in spices from India and different part of the world. However these reports are mainly confined to aflatoxins and ochratoxin A contamination [6-8]. This is the first report of CTN in black pepper, cumin, fenugreek, and dry ginger from Bihar.

The present study was conducted to assess the association of toxigenic mycoflora in spices and their mycotoxin producing potentiality. The natural contamination of AFs, OTA, and CTN was also examined in these spices. It has been observed that red chilli, black pepper, coriander, fenugreek, and dry ginger samples were highly susceptible to AFs, OTA, and CTN contamination. 


\section{Material and Methods}

2.1. Sampling. Nine different Indian spices comprise (55 samples of red chilli, 42 black pepper, 35 turmeric, 30 coriander, 28 cumin, 25 fennel, 25 caraway, 35 fenugreek, and 36 dry ginger) samples. A total 311 samples of different spices were collected from local markets of rural and urban areas of different district of Bihar (state). $100 \mathrm{gm}$ of each sample was kept into sterile brown envelop and stored at $4^{\circ} \mathrm{C}$ to arrest any mycotoxin formation before analysis.

2.2. Screening of Fungi. Samples were randomly placed on the freshly prepared PDA (potato dextrose agar), standard blotter paper and incubated at $28 \pm 2{ }^{\circ} \mathrm{C}$ for 7 days and examined daily. All plates were examined visually and by binocular stereomicroscope and counts were recorded. Fungal colonies of different morphological type were sub-cultured in culture tube containing PDA media. Identification of fungi was carried out by morphological characteristics and followed the taxonomic schemes of Maren [9] for genus Aspergillus, Pitt [10] for Penicillium, Leslie and Summerell [11] for Fusarium, and Crous et al. [12] for other genera.

2.3. Assessment of Potentiality of Toxigenic Fungi. A. flavus, A. parasiticus, $A$. ochraceus, $A$. terreus, $P$. citrinum, and $P$. verrucosum are well known toxigenic fungi to produce aflatoxins, ochratoxin A, and citrinin [13] and they were examined for their mycotoxins producing potentiality. The suspensions of isolated fungi were prepared using $0.5 \mathrm{McFarland}$ standard in normal saline that each $\mathrm{mL}$ of saline contains $10^{6}$ spores [14]. In all cases $50 \mu \mathrm{L}$ of each suspension was inoculated in $25 \mathrm{~mL}$ of freshly prepared broth media (SMKY media for aflatoxins and YES media for ochratoxin A and citrinin) and incubated at $28 \pm 2{ }^{\circ} \mathrm{C}$ for 10 days. When vigorous growth of fungus occurred the medium was filtered with Whatman No. 1 paper and the cultured filtrate was extracted with $10 \mathrm{~mL}$ of chloroform. In case of CTN, the culture filtered was acidified with $1 \mathrm{~N} \mathrm{HCL}$ to bring down the $\mathrm{pH}$ subsequently; then it was extracted with chloroform. The chloroform extract was evaporated to dryness and residue was dissolved in $1 \mathrm{~mL}$ of chloroform and qualitative and quantitative estimations of mycotoxins producing potentiality of fungi were done by the method of Diener and Davis [15] for aflatoxins producing potentiality of Aspergillus species. Methods of Schwenk et al. [16] and Davis et al. [17] were followed for CTN and OTA producing potentiality of mycoflora, respectively.

2.4. Qualitative and Quantitative Estimation of Mycotoxins by ELISA. Natural occurrence of AFs, OTA, and CTN in spices samples was analyzed by enzyme linked immunosorbent assay (ELISA). Samples were examined by AgraQuant Total Aflatoxin (COKAQ1000) for total AFs and AgraQuant Ochratoxin (COKAQ2000) for OTA from ROMER LAB (ASTRIA) and RIDASCREEN FAST citrinin Assay (6302) for CTN. For qualitative and quantitative estimation of total AFs, OTA and CTN, $20 \mathrm{gm}$ of grinded sample was mixed with $100 \mathrm{~mL}$ of $70 \%$ methanol and further blended for 3 minutes. The solutions were filtered and the supernatant was collected.
$4 \mathrm{~mL}$ of extract was transferred through cleanup columns; then the amount of AFs, OTA, and CTN was detected with specific ELISA kits and the optical density was recorded by the ELISA reader using a $450 \mathrm{~nm}$ filter with a differential filter of $630 \mathrm{~nm}$. The minimum detected amount of ELISA kit was $4 \mathrm{ng} / \mathrm{g}$ for AFs, $2 \mathrm{ng} / \mathrm{g}$ for OTA, and $15 \mathrm{ng} / \mathrm{g}$ for CTN (as mentioned by the manufacturer of Kits). Standard curve was prepared with standard solution provided with ELISA kits. The optical densities of the samples were compared to the optical density of standards and interpretative results were determined.

2.5. Confirmation by LC-MS/MS. Positive samples were further confirmed by LC-MS/MS using Agilent Poroshell 120 EC C18, $2.1 \times 100 \mathrm{~mm}$ column. $10 \mathrm{gm}$ of grinded sample was mixed with $40 \mathrm{~mL}$ of extraction solution containing Acetonitrile: Water $(40: 10, \mathrm{v} / \mathrm{v})$ and vortex vigorously for 5 minute and further shaken gently for another 45 minutes. The solution was filtered through $0.2 \mu$ nylon syringe filter. $2 \mathrm{~mL}$ of filtrate was taken and dried under fine stream of $\mathrm{N}_{2}$ gas further $1 \mathrm{~mL}$ of reconstitute solution of Acetonitrile: Water $(10: 40, \mathrm{v} / \mathrm{v})$ was added to prepare sample for LC-MS/MS analysis. $0.5 \mu \mathrm{L}$ of sample was injected into LC-MS/MS (Agilent 6410) containing the mobile phase of $0.1 \%$ formic acid in $5 \mathrm{mM}$ ammonium acetate and methanol [18].

2.6. Statistical Analysis. All the samples were analyzed in triplicate. Percent incidence was recorded as the mean value calculated from the number of samples analyzed from triplicate plating. ANOVA test was conducted to determine the differences in mean by one-way ANOVA using SPSS version 12.0 for MS/Windows (SPSS, Inc., Chicago, IL).

\section{Result and Discussion}

3.1. Mycobiotic Association. In our study, prevalence of mycoflora was isolated from spices; total 22 species belong to 7 different fungal genera (Table 1). Aspergillus was isolated from all spice samples whereas Penicillium were confined only to red chilli, black pepper, turmeric, cumin, coriander caraway fenugreek, and dry ginger samples (Figure 1). A. flavus contamination was highest in red chilli (32.3) followed by black pepper (28.3) and dry ginger (21.6) and lowest in coriander (8.0) samples. The present study revealed the wide range of fungal contamination in spices in which $A$. flavus was the most dominant fungal species among all fungi (Figure 2). Recently Rawat et al. [19] have also reported some of these fungi from stored medicinal plant samples. Bokhari [20] has also reported $A$. flavus and $A$. niger contamination from black pepper and green cardamom samples from Saudi Arabia. Moreover, the result from Table 1 also revealed that some of the fungi were only confined to specific spices. A. alternata, A. tamari, and C. globosum species were only confined to red chilli samples whereas $P$. citrinum and $A$. ochraceus were present in all spices except in fennel and coriander, respectively. It may be possible that some of the specific nutrients or essential oil present in these spices can have effect on the growth of specific fungi and further mycotoxin production. 
TABle 1: Percent incidence of fungal mycoflora isolated from different spices.

\begin{tabular}{|c|c|c|c|c|c|c|c|c|c|}
\hline \multirow{2}{*}{ Fungal species } & \multicolumn{9}{|c|}{ Name of the spices } \\
\hline & R. chi $^{\mathrm{a}}$ & B. pep $^{\text {b }}$ & Turm $^{c}$ & Cori $^{\mathrm{d}}$ & $\mathrm{Cumi}^{\mathrm{e}}$ & Fenn ${ }^{\mathrm{f}}$ & Cara $^{\mathrm{g}}$ & Fenu $^{\text {h }}$ & D. ging ${ }^{\mathrm{i}}$ \\
\hline Alternaria alternata & 2.3 & - & - & - & - & - & - & - & - \\
\hline Aspergillus parasiticus & - & 4.3 & - & - & - & - & - & - & 2.0 \\
\hline Aspergillus oryzae & - & 8.3 & - & - & 1.6 & - & 3.3 & - & 1.3 \\
\hline Aspergillus tamarii & 5.3 & - & - & - & - & - & - & - & - \\
\hline Aspergillus niger & 15.3 & 19.6 & 8.0 & 10.6 & 9.6 & 5.3 & 4.3 & 2.6 & 9.0 \\
\hline Aspergillus flavus & 32.3 & 28.3 & 9.6 & 8.0 & 16.6 & 12.3 & 15.3 & 19.6 & 21.6 \\
\hline Aspergillus ochraceus & 8.6 & 10.0 & 7.6 & - & 3.6 & 5.0 & 1.6 & 2.3 & 4.6 \\
\hline Aspergillus versicolor & 11.4 & 7.65 & - & - & - & - & - & - & - \\
\hline Aspergillus fumigatus & - & - & - & 2.0 & - & - & - & - & 4.6 \\
\hline Aspergillus terreus & - & 6.3 & - & - & 2.6 & 1.3 & - & - & 2.6 \\
\hline Aspergillus sydowii & - & - & - & 2.6 & - & - & 4.0 & 2.6 & - \\
\hline Penicillium citrinum & 12.6 & 19.3 & 4.0 & 7.6 & 3.3 & - & 2.3 & 7.6 & 16.3 \\
\hline Penicillium islandicum & - & - & - & - & - & - & 1.6 & - & - \\
\hline Penicillium verrucosum & 8.6 & 10.0 & 8.0 & 6.3 & - & - & - & 6.0 & 8.6 \\
\hline Penicillium purpurogenum & - & 1.3 & - & - & - & - & - & - & 2.6 \\
\hline Penicillium cyclopium & - & - & - & - & - & - & 1.6 & - & - \\
\hline Fusarium oxysporum & - & 5.6 & 5.3 & - & 6.6 & - & 3.3 & - & 2.3 \\
\hline Fusarium moniliforme & 6.3 & 9.6 & 4.6 & - & - & 3.0 & - & 1.6 & 3.0 \\
\hline Chaetomium globosum & 1.4 & - & - & - & - & - & - & - & - \\
\hline Rhizopus nigricans & - & 6.3 & - & 4.3 & 2.5 & - & - & - & - \\
\hline Rhizopus oryzae & 4.3 & 6.6 & - & - & 2.6 & 2.3 & - & 4.0 & 2.6 \\
\hline Mucor hiemalis & 7.0 & 3.0 & - & 2.6 & - & 1.6 & - & - & - \\
\hline
\end{tabular}

${ }^{\mathrm{a}}$ Red chilli, ${ }^{\mathrm{b}}$ black pepper, ${ }^{\mathrm{c}}$ turmeric, ${ }^{\mathrm{d}}$ coriander, ${ }^{\mathrm{e}}$ cumin, ${ }^{\mathrm{f}}$ fennel, ${ }^{\mathrm{g}}$ caraway, ${ }^{\mathrm{h}}$ fenugreek, and ${ }^{\mathrm{i}}$ dry ginger.

Few earlier reports are available regarding inhibitory effects of some spices on the growth of fungi and their mycotoxin production [21, 22]. It has been also observed that red chilli, black pepper, and dry ginger are susceptible substrate for growth of $A$. niger, A. flavus, $P$. citrinum, $P$. verrucosum, and $F$. moniliforme whereas coriander, turmeric, cumin, fennel, and fenugreek are mildly resistant.

3.2. Toxic Potentiality of Isolated Fungi. Aflatoxins, ochratoxin A, and citrinin producing potentiality of A. flavus, A. parasiticus, A. ochraceus, $A$. terreus, $P$. citrinum, and $P$. verrucosum isolated from spices samples were examined (Table 2). Toxigenic A. flavus were isolated from all spices. $56 \%$ isolates of A. flavus from red chilli samples were highly toxic and produce aflatoxins up to $33.6 \mu \mathrm{g} / \mathrm{L}$ whereas aflatoxins produced by $A$. parasiticus were less potential than A. flavus. A. ochraceus and $P$. verrucosum produce OTA from all spices, except in cumin. CTN was only produced by $P$. citrinum, up to $18.5 \mu \mathrm{g} / \mathrm{L}$ and it was only confined to red chilli, black pepper, coriander, cumin, fenugreek, and dry ginger samples whereas none of the isolates of $A$. terreus were found toxigenic.

3.3. Natural Occurrence of Mycotoxins in Spices. AFs $\left(\mathrm{AFB}_{1}\right.$, $\mathrm{AFB}_{2}, \mathrm{AFG}_{1}$, and $\left.A \mathrm{AF}_{2}\right), \mathrm{OTA}$, and CTN were detected from different spices (Figures 3 and 4). All 9 types of spice samples were analyzed and it has been observed that some of

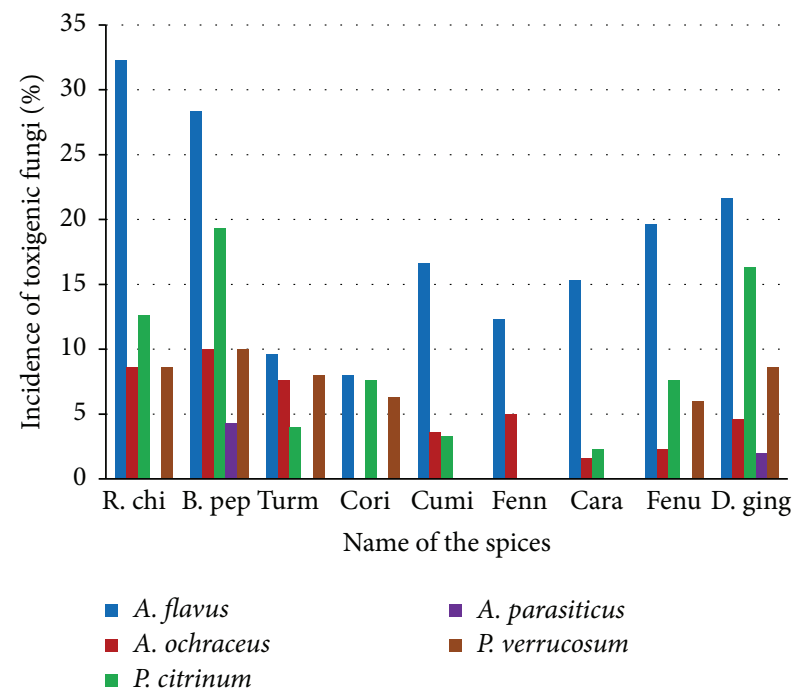

FIGURE 1: Percent incidence of toxigenic fungal contamination in spices samples.

the samples were only contaminated to aflatoxin $B_{1}$ or $B_{1} B_{2}$ or $G_{1}$ or $G_{1} G_{2}$ and some were positive to $B_{1} B_{2} G_{1} G_{2}$ whereas OTA and CTN were also detected from these samples (Table 3). 47 out of 55 samples of red chilli were contaminated with aflatoxins in which 31 samples were positive to $\mathrm{AFB}_{1}$. 


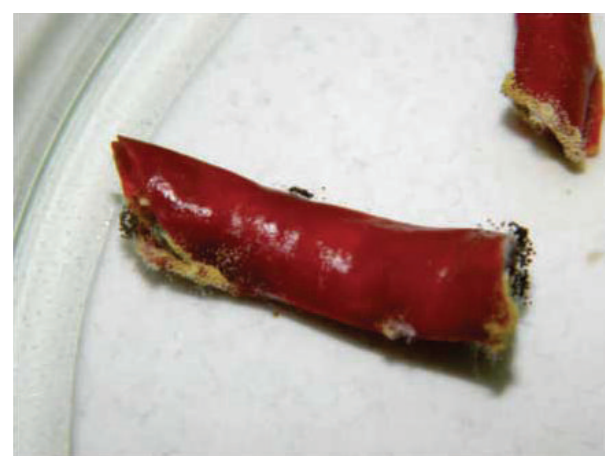

(a)

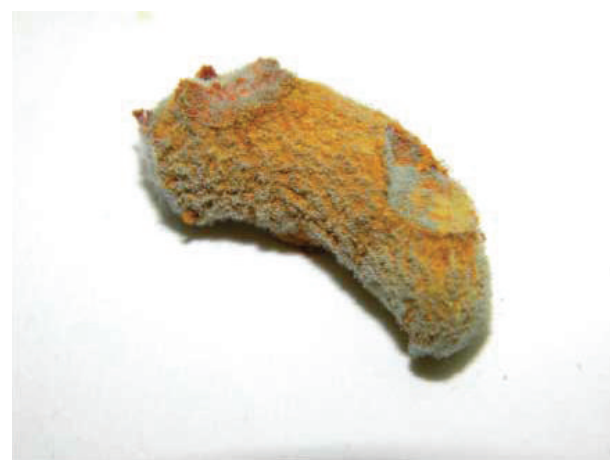

(c)

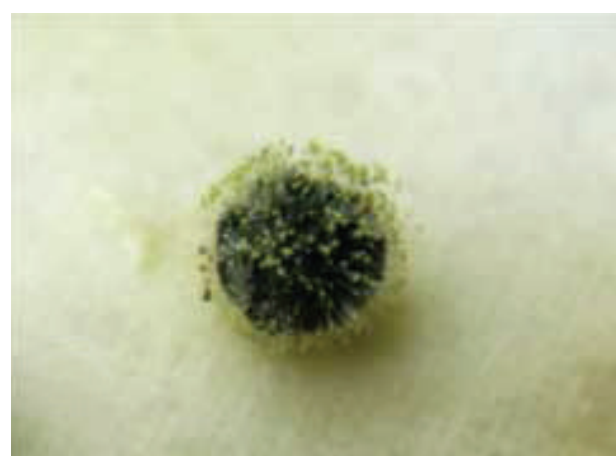

(b)

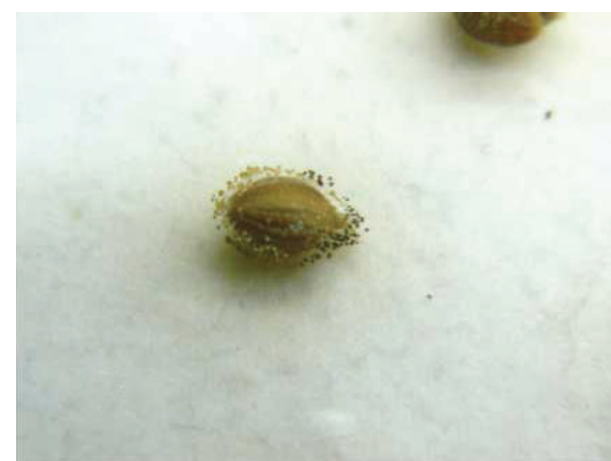

(d)

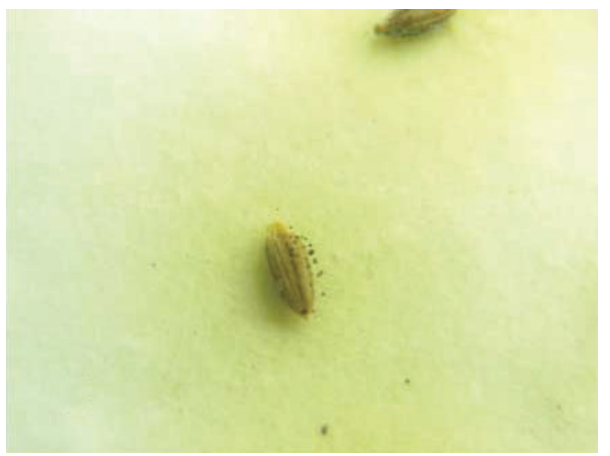

(e)

Figure 2: Fungal association of toxigenic fungi in different spices. (a) Red chilli associated with A. flavus and A. niger, (b) A. flavus, A. parasiticus, $A$. niger, and the other fungal contamination in black pepper, (c) fungal contamination in turmeric, (d) coriander associatedwith different fungi, and (e) association of A. flavus and A. niger in cumin.

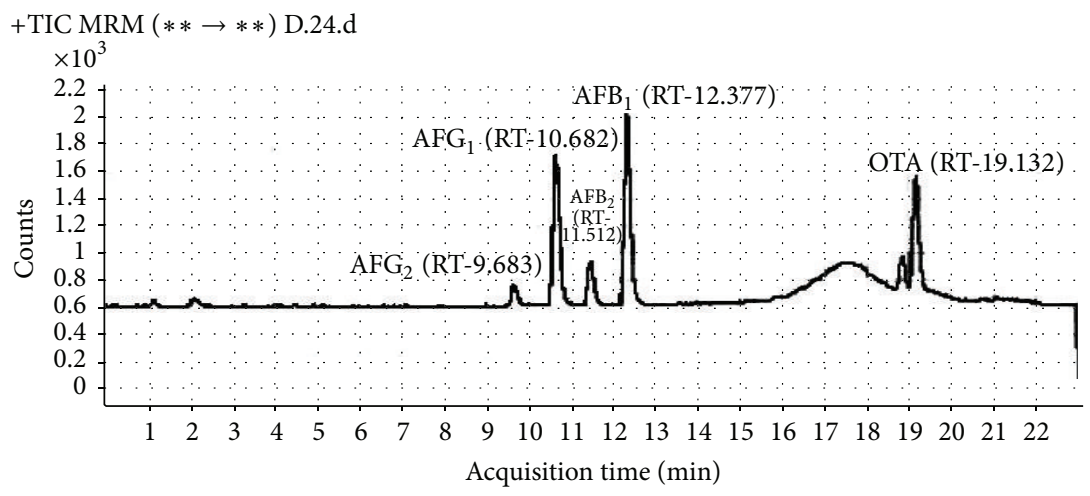

FIGURE 3: LC-MS/MS chromatogram of $\mathrm{AFs}\left(\mathrm{AFB}_{1}, \mathrm{AFB}_{2}, \mathrm{AFG}_{1}\right.$, and $\left.\mathrm{AFG}_{2}\right)$ and $\mathrm{OTA}$ for red chilli sample having maximum contamination. 
TABLE 2: Mycotoxin producing potentiality of toxigenic fungi from different spices.

\begin{tabular}{|c|c|c|c|c|c|}
\hline Sn & Spice & Fungi examined & $\% \operatorname{tox}^{a}$ & Mycotoxin detected & Potential range $(\mu \mathrm{g} / \mathrm{L})$ \\
\hline \multirow{4}{*}{1} & \multirow{4}{*}{ R. chi } & A. flavus & 56.0 & AFs & $4.3-33.6$ \\
\hline & & A. ochraceus & 41.6 & OTA & $2.8-18.6$ \\
\hline & & P. citrinum & 31.2 & CTN & $15.6-28.3$ \\
\hline & & P. verrucosum & 30.0 & OTA & $3.5-8.6$ \\
\hline \multirow{6}{*}{2} & \multirow{6}{*}{ B. pep } & A. flavus & 45.4 & AFs & $6.3-26.4$ \\
\hline & & A. parasiticus & 26.6 & AFs & $4.8-9.6$ \\
\hline & & A. ochraceus & 45.0 & OTA & $5.4-22.6$ \\
\hline & & A. terreus & 0 & - & - \\
\hline & & P. citrinum & 44.4 & CTN & $15.4-20.5$ \\
\hline & & P. verrucosum & 25.0 & OTA & $4.6-13.8$ \\
\hline \multirow{4}{*}{3} & \multirow{4}{*}{ Turm } & A. flavus & 20.0 & AFs & $4.4-11.3$ \\
\hline & & A. ochraceus & 40.0 & OTA & $2.1-18.9$ \\
\hline & & P. citrinum & 0 & - & - \\
\hline & & P. verrucosum & 16.6 & OTA & $3.7-6.1$ \\
\hline \multirow{3}{*}{4} & \multirow{3}{*}{ Cori } & A. flavus & 38.8 & AFs & $5.2-13.7$ \\
\hline & & P. citrinum & 26.6 & CTN & $18.7-20.9$ \\
\hline & & P. verrucosum & 20.0 & OTA & $6.8-16.1$ \\
\hline \multirow{4}{*}{5} & \multirow{4}{*}{ Cumi } & A. flavus & 46.6 & AFs & $5.8-18.2$ \\
\hline & & A. ochraceus & 0 & - & - \\
\hline & & A. terreus & 0 & - & - \\
\hline & & P. citrinum & 13.3 & CTN & $16.0-18.5$ \\
\hline \multirow{3}{*}{6} & \multirow{3}{*}{ Fenn } & A. flavus & 45.0 & AFs & $8.7-24.3$ \\
\hline & & A. ochraceus & 38.8 & OTA & $6.5-8.4$ \\
\hline & & A. terreus & 0 & - & - \\
\hline \multirow{3}{*}{7} & \multirow{3}{*}{ Cara } & A. flavus & 40.9 & AFs & $6.4-16.7$ \\
\hline & & A. ochraceus & 22.2 & OTA & $6.1-15.4$ \\
\hline & & P. citrinum & 0 & - & - \\
\hline \multirow{4}{*}{8} & \multirow{4}{*}{ Fenu } & A. flavus & 35.0 & AFs & $6.4-19.7$ \\
\hline & & A. ochraceus & 40.0 & OTA & $3.5-20.1$ \\
\hline & & P. citrinum & 20.0 & CTN & $17.2-19.2$ \\
\hline & & P. verrucosum & 0 & - & - \\
\hline \multirow{6}{*}{9} & \multirow{6}{*}{ D. ging } & A. flavus & 44.0 & AFs & $5.8-24.2$ \\
\hline & & A. parasiticus & 27.7 & AFs & $6.4-8.1$ \\
\hline & & A. ochraceus & 33.3 & OTA & $3.1-16.7$ \\
\hline & & A. terreus & 0 & - & - \\
\hline & & P. citrinum & 38.8 & CTN & $16.4-22.3$ \\
\hline & & P. verrucosum & 30.0 & OTA & $2.4-8.7$ \\
\hline
\end{tabular}

${ }^{a}$ Percentage of toxigenic isolates of fungi.

Earlier Golge et al. [23] also reported the level of aflatoxins in commercially used Turkish red chilli. CTN contamination was highly observed in dry ginger whereas none of the samples of turmeric, fennel, and caraway were CTN contaminated. OTA were detected from all different spices, except in cumin. Fazekas et al. [24] also reported $\mathrm{AFB}_{1}, \mathrm{AFB}_{2}, \mathrm{AFG}_{1}$, $\mathrm{AFG}_{2}$, and OTA contamination in spices from Hungary. It has been observed that CTN contamination is mainly confined to the dry ginger, red chilli, coriander, and black pepper samples. These samples are highly contaminated with $P$. citrinum or $P$. verrucosum or both and they were known to produce CTN on substrate. So, it may be possible that dry ginger, red chilli, coriander, and black pepper are susceptible for $P$. citrinum and $P$. verrucosum growth and further mycotoxin productions.

Natural occurrence of AFs, OTA, and CTN in spices has been shown in Table 4. All spices were contaminated with AFs and detected amount is maximum compared to OTA and CTN except in fennel. Highest amount of AFs was recorded in red chilli samples $(219.6 \mathrm{ng} / \mathrm{g})$ and OTA contamination was maximum in black pepper (154.1 ng/g). Earlier Jalili and Jinap [25] have reported that $65 \%$ of chilli samples were contaminated with AFs level in the range of $0.2-79.7 \mathrm{ng} / \mathrm{g}$ and $81.25 \%$ of samples were positive to OTA in the range 
TABLE 3: Number of different spice samples contaminated with aflatoxins, ochratoxin A, and citrinin.

\begin{tabular}{|c|c|c|c|c|c|c|c|c|c|}
\hline \multirow{3}{*}{ Spices } & \multirow{3}{*}{ Number of samples analyzed } & \multicolumn{8}{|c|}{ Number of samples with different mycotoxins contamination } \\
\hline & & & & & & & & OTA & CTN \\
\hline & & $\mathrm{B}_{1}$ & $\mathrm{G}_{1}$ & $\mathrm{~B}_{1} \mathrm{~B}_{2}$ & $\mathrm{G}_{1} \mathrm{G}_{2}$ & $\mathrm{~B}_{1} \mathrm{~B}_{2} \mathrm{G}_{1} \mathrm{G}_{2}$ & Total & 011 & 611 \\
\hline Red chilli & 55 & 31 & 2 & 9 & 1 & 4 & 47 & 40 & 26 \\
\hline Black pepper & 42 & 19 & 1 & 5 & 2 & 5 & 32 & 33 & 19 \\
\hline Turmeric & 35 & 10 & 0 & 7 & 3 & 4 & 24 & 20 & 0 \\
\hline Coriander & 30 & 15 & 0 & 4 & 1 & 2 & 22 & 09 & 12 \\
\hline Cumin & 28 & 12 & 2 & 3 & 0 & 1 & 18 & 0 & 6 \\
\hline Fennel & 25 & 08 & 0 & 4 & 1 & 1 & 14 & 14 & 0 \\
\hline Caraway & 25 & 08 & 1 & 3 & 0 & 1 & 13 & 12 & 0 \\
\hline Fenugreek & 35 & 15 & 0 & 3 & 2 & 3 & 23 & 18 & 13 \\
\hline Dry ginger & 36 & 16 & 2 & 7 & 0 & 3 & 28 & 20 & 16 \\
\hline
\end{tabular}

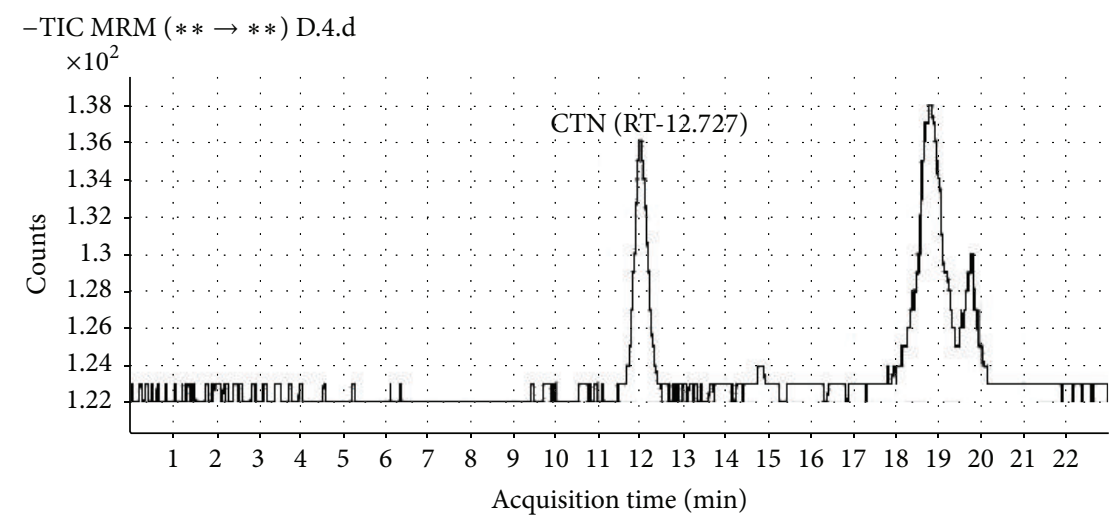

FIGURE 4: LC-MS/MS chromatogram of CTN for ginger sample having maximum contamination.

of $0.2-101.2 \mathrm{ng} / \mathrm{g}$. Ozbey and Kabak [26] have also reported $30.4 \%$ AFs contamination and $17.4 \%$ of OTA contamination in black pepper powder. In present investigation, only $30 \%$ of coriander samples were positive to OTA and none of the cumin samples were positive. It may be due to essential oil (cuminaldehyde) of the cumin which inhibited the growth of OTA producing fungi (A. ochraceus and P. verrucosum) and OTA production. Earlier, Hua et al. [27] have reported that essential oil of cinnamon inhibits the growth of $A$. ochraceus and ochratoxin A production. Ferreira et al. [28] have reported that turmeric has the inhibitory effect on the growth of $A$. flavus and mycotoxin production but in our report $68.5 \%$ of turmeric was AFs contaminated and $57.1 \%$ was OTA contaminated with the detectable amount of $163.8 \mathrm{ng} / \mathrm{g}$ and $125 \mathrm{ng} / \mathrm{g}$, respectively (Figure 5).

\section{Conclusion}

On the basis of the present study, it may be concluded that the red chilli, black pepper, and dry ginger are susceptible substrate for fungal growth and subsequent mycotoxin productions. All 9 types of spices were contaminated with AFs. This is the first report of CTN contamination in black pepper, cumin, fenugreek, and dry ginger from Bihar state (India). Red chilli, black pepper, and dry ginger are the most

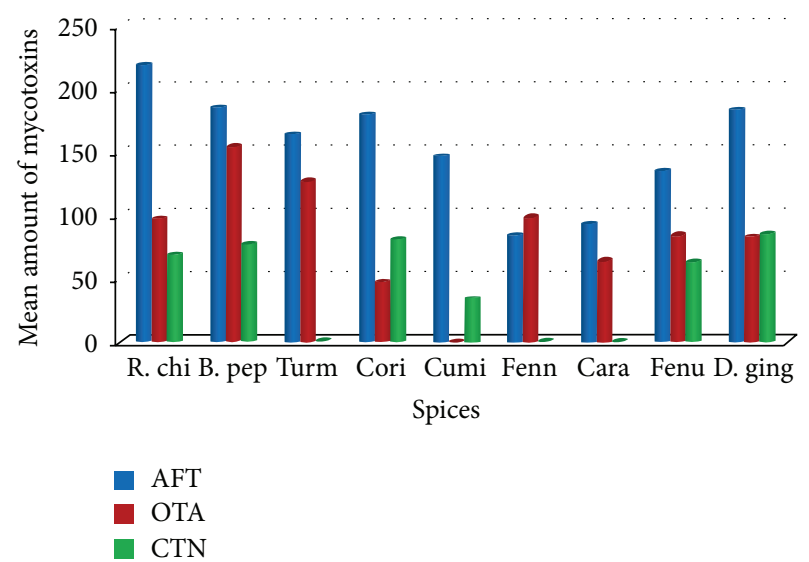

FIGURE 5: Amount of total aflatoxins, ochratoxin A, and citrinin in different spices.

contaminated spices in which AFs, OTA, and CTN were present in high concentration. Fennel, caraway, and cumin are the spices which can be considered a bit resistant to mycotoxigenic fungi and mycotoxin contamination. Further research is needed to isolate the active ingredient or the essential oil of these spices, which plays a vital role in the growth of toxigenic fungi and further toxin production. It is very 


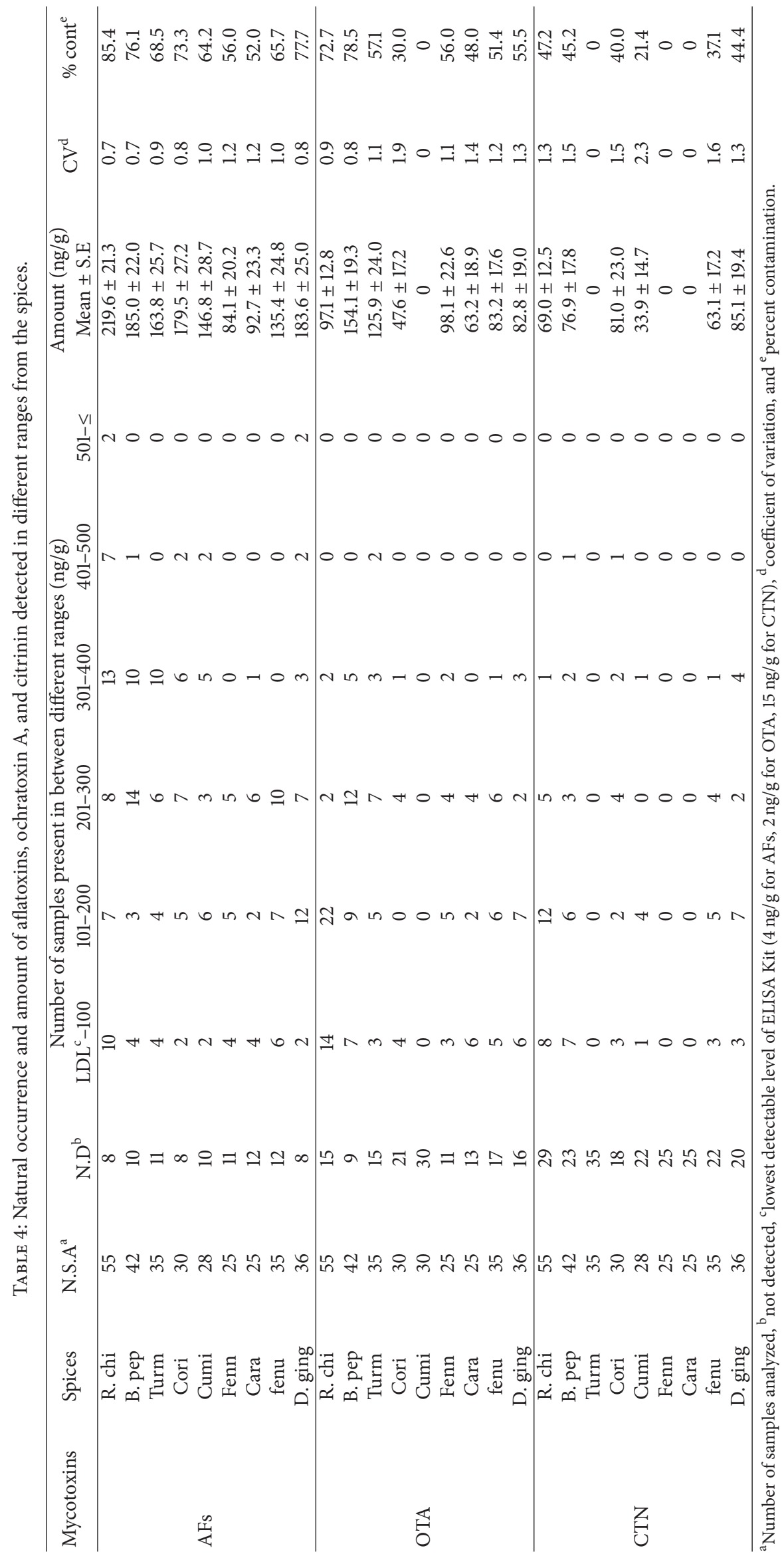


important to care in processing, handling, transportation, and modification in storage system to reduce the production of hazardous mycotoxins in spices.

\section{Conflict of Interests}

The authors declared that there is no any conflict of interests.

\section{Acknowledgments}

Authors are thankful to Professor (Dr.) Nandji Kumar, exVice Chancellor, Magadh University, Bodh Gaya, and the Principal, A. N. College, Patna, Bihar, India for providing laboratory facilities. They are also thankful to Dr. Antonio Logerico, Research Leader, Italy, for providing toxigenic strains of fungi and Spectro Analytical Labs Limited, India (CIN no. U74220DL1998PLC092698), for LS-MS/MS analysis of samples.

\section{References}

[1] S. R. Power, "Present scenario of Indian spice industry and its trend in production and export," Asian Journal of Management, vol. 4, no. 3, pp. 197-204, 2013.

[2] P. W. Sherman and J. Billing, "Darwinian gastronomy: why we use spices: spices taste good because they are good for us," BioScience, vol. 49, no. 6, pp. 453-463, 1999.

[3] H. Qureshi, S. S. Ali, M. Iqbal, A. A. Siddiqui, N. A. Khan, and S. S. Hamin, "Aflatoxins and hepatitis B, C viral associated hepatocarcinogenesis," Journal of Cell Science \& Therapy, vol. 5, no. 5, p. 179, 2014.

[4] P. Jeswal, "Cumulative effect of Ochratoxin A and citrinin on induction of hepatorenal carcinogenesis in mice (Mus musculus)," Biomedical Letters, vol. 52, pp. 269-275, 1995.

[5] G. Wichmann, O. Herbarth, and I. Lehmann, "The mycotoxins citrinin, gliotoxin, and patulin affect interferon- $\gamma$ rather than interleukin-4 production in human blood cells," Environmental Toxicology, vol. 17, no. 3, pp. 211-218, 2002.

[6] M. A. Ath-Har, H. S. Prakash, and H. S. Shetty, "Mycoflora of Indian spices with special reference to aflatoxigenic producing isolates of Aspergillus flavus," Indian Journal of Microbiology, vol. 28, pp. 125-127, 1988.

[7] C. Zaied, S. Abid, C. Bouaziz, S. Chouchane, M. Jomaa, and H. Bacha, "Ochratoxin A levels in spices and dried nuts consumed in Tunisia," Food Additives and Contaminants: Part B Surveillance, vol. 3, no. 1, pp. 52-57, 2010.

[8] H. Tosun and R. Arslan, "Determination of aflatoxin B1 levels in organic spices and herbs," The Scientific World Journal, vol. 2013, Article ID 874093, 4 pages, 2013.

[9] A. K. Maren, Identification of Common Aspergillus Species, Centraalbureau voor Schimmelcultures, Utrecht, The Netherlands, 2002.

[10] J. I. Pitt, A Laboratory Guide to Common Penicillium Species, International Government Publication, North Ryde, Australia, 1988.

[11] J. F. Leslie and B. A. Summerell, The Fusarium Laboratory Manual, Blackwell Publishing, London, UK, 2006.

[12] P. W. Crous, G. D. M. Verkley, J. Z. Groenewald, and R. A. Samson, Fungal Diversity, APS Press, 2009.
[13] J. I. Pitt, “Toxigenic fungi and mycotoxins," British Medical Bulletin, vol. 56, no. 1, pp. 184-192, 2000.

[14] M. A. Pfaller, L. Burmeister, M. S. Bartlett, and M. G. Rinaldi, "Multicenter evaluation of four methods of yeast inoculum preparation," Journal of Clinical Microbiology, vol. 26, no. 8, pp. 1437-1441, 1988.

[15] U. L. Diener and N. D. Davis, "Aflatoxin production by isolates of Aspergillus flavus," Phytopathology, vol. 56, no. 12, pp. 13901393, 1966.

[16] E. Schwenk, G. J. Alexander, A. M. Gold, and D. F. Stevens, "Biogenesis of citrinin," The Journal of Biological Chemistry, vol. 233, no. 5, pp. 1211-1213, 1958.

[17] N. D. Davis, G. A. Sansing, T. V. Ellenburg, and U. L. Diener, "Medium-scale production and purification of ochratoxin A, a metabolite of Aspergillus ochraceus," Applied Microbiology, vol. 23, no. 2, pp. 433-435, 1972.

[18] R. Zheng, H. Xu, W. Wang, R. Zhan, and W. Chen, "Simultaneous determination of aflatoxin $B_{1}, B_{2}, G_{1}, G_{2}$, ochratoxin $A$, and sterigmatocystin in traditional Chinese medicines by LCMS-MS," Analytical and Bioanalytical Chemistry, vol. 406, no. 13, pp. 3031-3039, 2014.

[19] A. Rawat, S. Mahajan, A. Gupta, R. K. Agnihotri, N. Wahi, and R. Sharma, "Detection of toxigenic fungi and mycotoxins in some stored medicinal plant samples," International Journal of Applied Sciences and Biotechnology, vol. 2, no. 2, 2014.

[20] F. M. Bokhari, "Spices mycobiota and mycotoxins available in Saudi Arabia and their abilities to inhibit growth of some toxigenic fungi," Mycobiology, vol. 35, no. 2, pp. 47-53, 2007.

[21] J. Tian, X. Ban, H. Zeng, J. He, B. Huang, and Y. Wang, "Chemical composition and antifungal activity of essential oil from Cicuta virosa L. var. latisecta Celak," International Journal of Food Microbiology, vol. 145, no. 2-3, pp. 464-470, 2011.

[22] A. K. Mishra, A. Mishra, H. K. Kehri, B. Sharma, and A. K. Pandey, "Inhibitory activity of Indian spice plant Cinnamomum zeylanicum extracts against Alternaria solani and Curvularia lunata, the pathogenic dematiaceous moulds," Annals of Clinical Microbiology and Antimicrobials, vol. 8, article 9, 2009.

[23] O. Golge, F. Hepsag, and B. Kabak, "Incidence and level of aflatoxin contamination in chilli commercialised in Turkey," Food Control, vol. 33, no. 2, pp. 514-520, 2013.

[24] B. Fazekas, A. Tar, and M. Kovács, "Aflatoxin and ochratoxin A content of spices in Hungary," Food Additives and Contaminants, vol. 22, no. 9, pp. 856-863, 2005.

[25] M. Jalili and S. Jinap, "Natural occurrence of aflatoxins and ochratoxin A in commercial dried chili," Food Control, vol. 24, no. 1-2, pp. 160-164, 2012.

[26] F. Ozbey and B. Kabak, "Natural co-occurrence of aflatoxins and ochratoxin A in spices," Food Control, vol. 28, no. 2, pp. 354-361, 2012.

[27] H. Hua, F. Xing, J. N. Selvaraj et al., "Inhibitory effect of essential oils on Aspergillus ochraceus growth and ochratoxin a production," PLoS ONE, vol. 9, no. 9, Article ID e108285, 2014.

[28] F. D. Ferreira, S. A. G. Mossini, F. M. D. Ferreira et al., "The inhibitory effects of Curcuma longa L. essential oil and curcumin on Aspergillus flavus link growth and morphology," The Scientific World Journal, vol. 2013, Article ID 343804, 6 pages, 2013. 

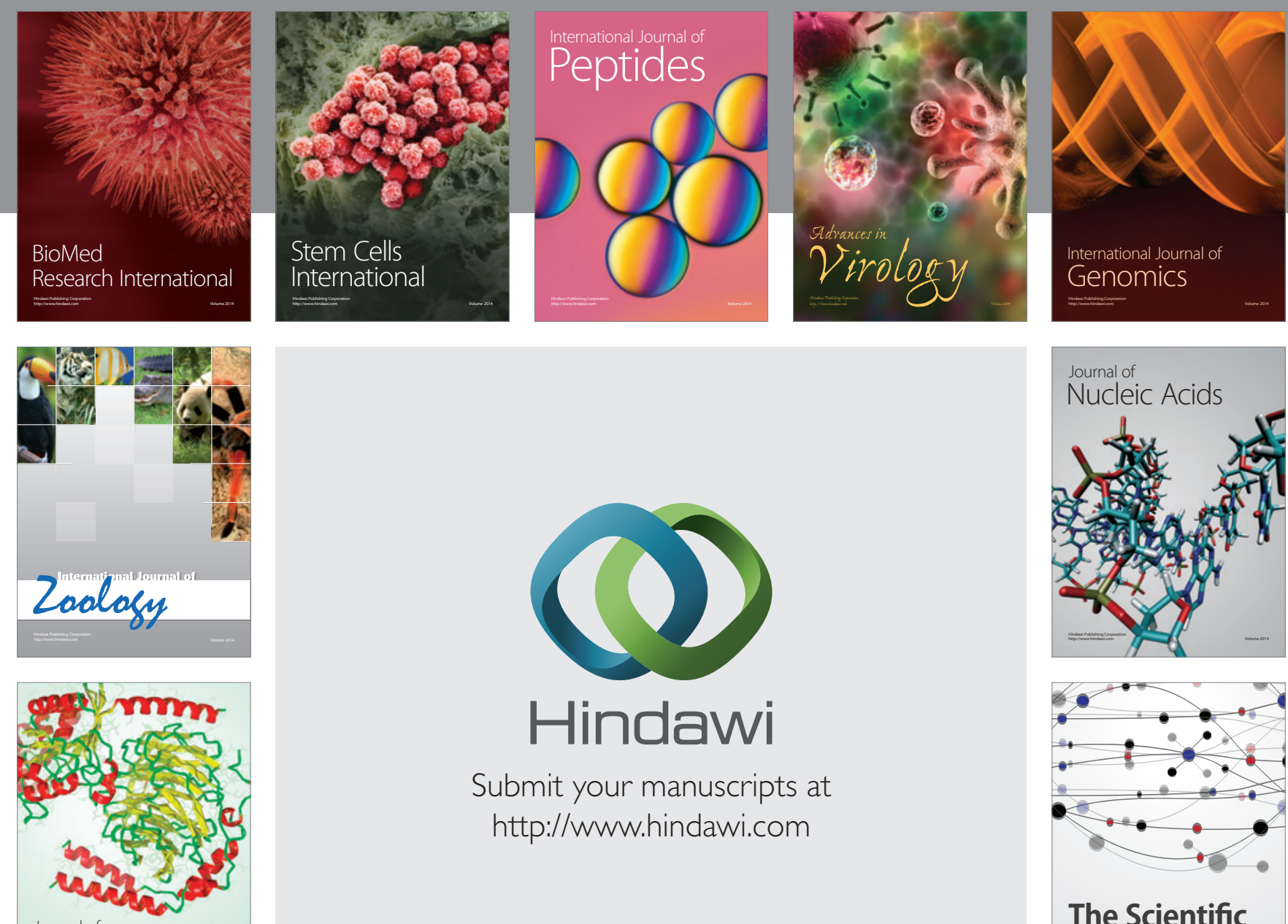

Submit your manuscripts at

http://www.hindawi.com

Journal of
Signal Transduction
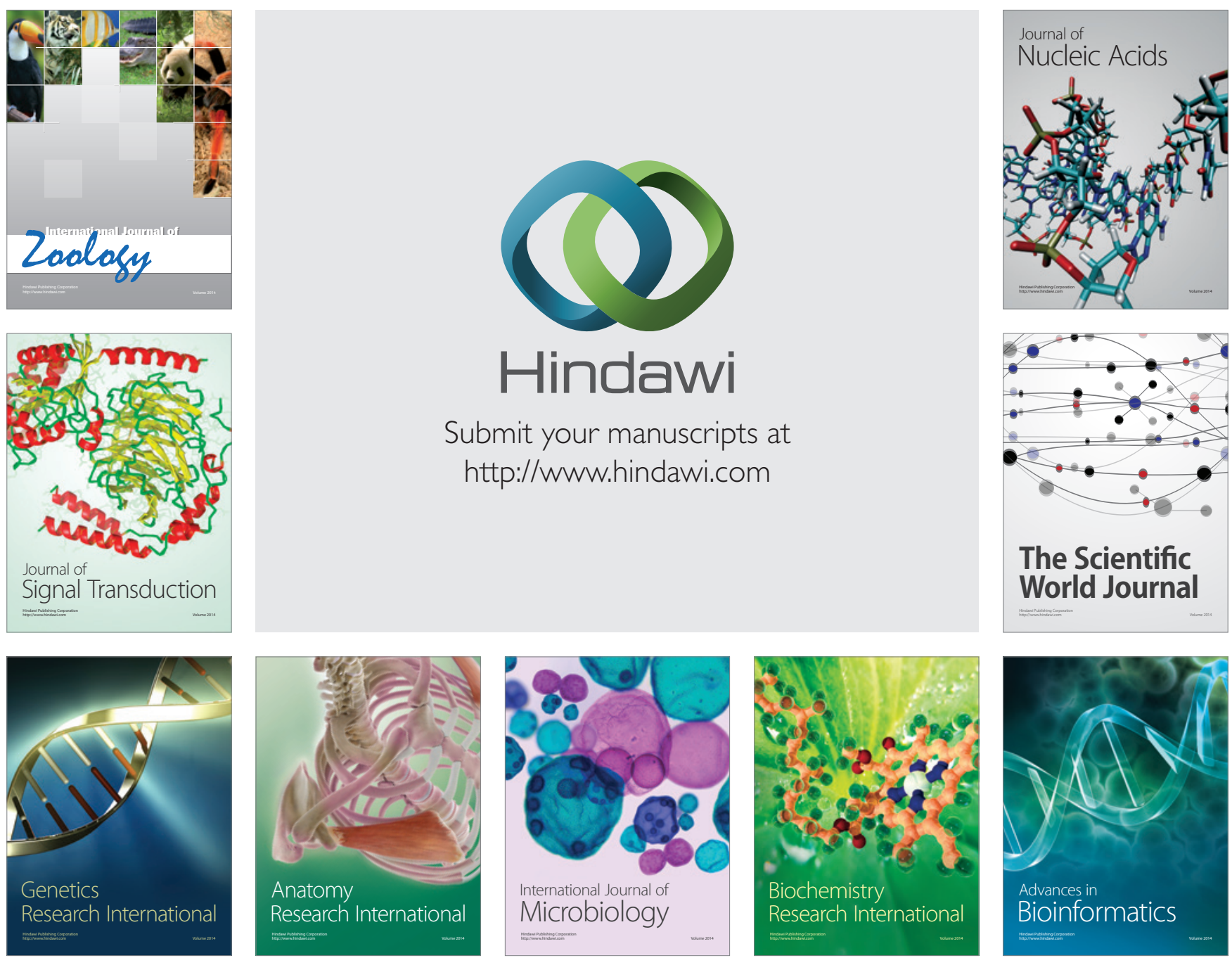

The Scientific World Journal
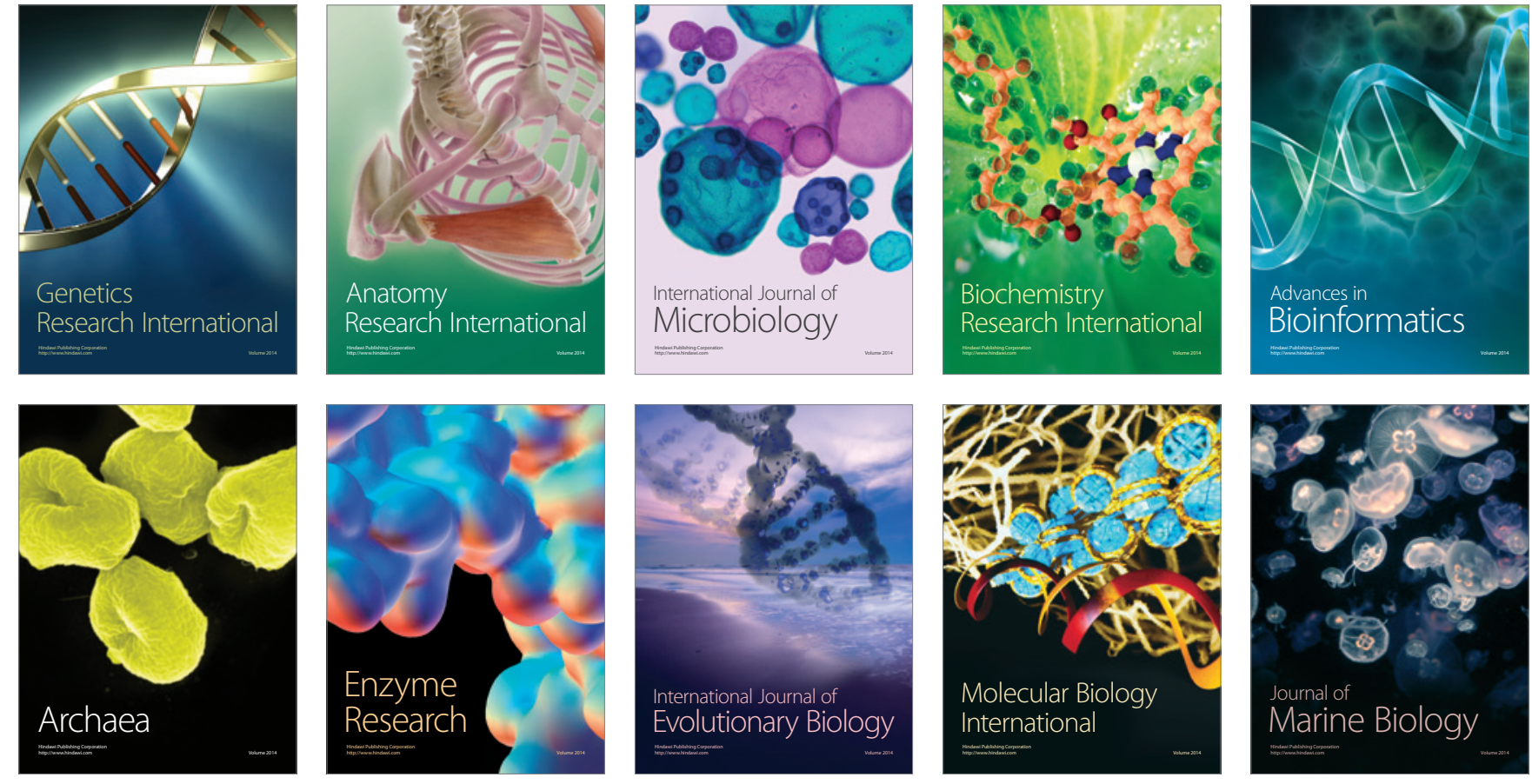